\title{
INSTITUTO DE DIREITO COMPARADO DA UNIVERSIDADE DO PARANÁ
}

\section{Exposição justificativa para sua criação - Visão panorâmica das atividades de pesquisa comparatista no universo.}

\author{
o. Martins Gomes \\ Professor Catedrático de Direito Internacional \\ Privado da Faculdade de Direito da Universidade \\ do Paraná
}

1 Se é verdade que o exame comparativo do direito entre os povos não escapou jamais ao espírito investigador dos juristas E legisladores, através dos tempos, o direito comparado, entretanto, recebeu um impulso ostensivo e ordenado quando foram criadas as cátedras de direito comparado nos estabelecimentos de ensino superior da Europa, notadamente na Universidade de Paris, em 1846. Para tal incremento, muito contribuiram, nessa época, os estudos de direito internacional privado desenvolvidos por SAVIGNY na Alemanha, LAINÉ na França, LAURENT na Bélgica, FIORE na Itália, STORY nos Esstados Unidos e outros especialistas na matéria.

Mas, os centros culturais de pesquisas jurídicas encontraram sua maior receptividade no presente século, com a criação de Institutos adequados no estudo do direito comparado. E o primeiro Instituto de direito comparado, no murdo, foi fundado em 1916, na Universidade de Munich, na Alemanha, conforme informações do eminente comparatista RENÉ DAVID, em sua excelente obra "Droit Civil Comparé", publicada em Paris em 1950, da qual com proveito nos serviremos ainda nêste estudo para obtenção de outros dados informativos. Acen- 
tua, porém, êsse escritor que, fora do âmbito das Universidades, a Sociedade de Legislação Comparada, fundada em 1869, com sede em Paris, é a mais antiga sociedade de tal natureza existente no globo, agrupando membros franceses e estrangeiros, para estudos de direito comparado, com atividades permanentes, publicação de sua revista e organização de congressos internacionais de direito comparado, como o de Paris em 1900. Possui ainda essa Sociedade ramificações na Europa e na América, sendo de notar também, entre as suas iniciativas, as Jorradas de direito franco-latino-americanas, como as realizadas, no ano de 1948, em Paris e em Montevidéu, e em 1954 em São Faulo.

Dentre os mais prestigiosos Institutos são de mencionar: na França, o. Instituto de Direito Comparado da Universidade de Paris, de notável atividade e prestígio, e cuja origem remonta a 1920, cumprindo observar que, após a segunda guerra mundial, estando na presidência da Sociedade de Legislação Comparada o emérito professôr NIBOYET, foram reforçados os laços que uniam as duas importantes entidades, para um escopo comum; na Itália, o Instituto de Estudos Legislativos criado em Roma em 1925, e outros Institutos de direito comparado fundados pelo acatado comparatista italiano professor. MARIO ROTONDI, na Universidade de Pavia e na Universidade Católica de Milão.

Digno de menção, na Itália, é o Instituto Internacional de Roma para Unificação do Direito Privado, instalado em 1928, por iniciativa do govêrno italiano e sob os auspícios da extinta Sociedade das Naçõees.

Outros Institutos de direito comparado foram fundados em países da Europa e da América, como se pode ver, quanto a esta, no artigo do professor DE SOLA CAÑIZARES "O Direito Comparado na América Latina", publicado no Boletim da Sociedade de Legislação Comparada (1947, pág. 229).

A Inglaterra conta com uma pleidade de comparatistas, professôres nas escolas de direito de Londres, Cambridge, Oxford, Manchester etc., sendo de salientar, na atualidade, o nome respeitável do professor H. C. GUTTERIDGE, de Cambridge, au- 
tor de obras de alta valia. Em Londres, o Institute of Advence Legal Studies, possuindo enorme biblioteca e elevado patrimônio, se dedica ás investigações dos direitos estrangeiros.

Duas prestigiosas entidades, fundadas no século passado, com sede em Londres, são a Society of Comparative Legislation and International Law, que publica conceituada revista, e a International Law Association, com ramos nacionais em muitos países, dedicando-se, sobretudo, á comparação dos diferentes sistemas legislativos.

Tais estudos hão despertado igual interêsse nos diversos países da Commonweath, como o Canadá, a Africa do Sul e o Ceilão.

Concluindo as referências á Europa, impõe-se citar o Instituto de Direito Internacional, de que participa um número limitado de juristas de renome universal. Fundado em Gand em 1873, publica valioso "Anuário" de suas sábias resoluções fm direito internacional público e direito internacional privado. Recentemene, em virtude de decisão do Bureau de l' Institut, tomada em Paris, foram reunidas em volume impresso, no seu texto exato, as 170 resoluções aprovadas pelo Instituto, de 1873 a 1956.

2 Quando surgiu e se fêz conhecido o Instituto de Direito Comparado da Faculdade de Direito de Cordoba, na Argentina, em 1939, o eminente mestre Edouard LAMBERT o saudou com entusiasmo, dizendo: "Acolho essa nova iniciativa com uma grande satisfação. Traz ela um precioso encorajamento á propaganda, encetada pelo Instituto de Direito Comparado de Lyon, a favor da constituição duma rêde internacional de centros de direito comparado, unidos numa cooperação contínua para a defesa do humanismo jurídico e a direção do estudo do direito voltado para seus aspectos de ciência aplicada e de ciência internacional." Lembrou LAMBERT, nessa ocasião, que, nc: ano anterior, havia sido inaugurado em Montevidéu, aos cuidados do professor Eduardo COUTURE, um primeiro Instituto de Direito Comparado, encarado como um dos ramos naturais dum Instituto central ibero-americano. E assim finaliza sua apreciação: " $E$ isso nos autoriza a considerar a recente 
creação da Faculdade de Direito de Cordoba como um dos pontos de partida - um ponto de partida importante - e não como um ponto de chegada, da participação da América Latina na crganização internacional do direito comparado". (Bulletin de l'Institut de Droit Comparé de Lyon, fasc. de março - junho de 1939, pág. 69).

De outros Institutos de direito comparado fundados na América Latina dá notícia RENÉ DAVID, filiados a Ũniversidades e faculdades de direito, e tais são: no México, em 1940; em Porto Rico, em 1942; no Panamá, em 1944; em Bogotá, em 1947; em Buenos Aires, em 1948; e no Rio de Janeiro, em 1949.

$\mathrm{E}$ faz ver que os Institutos de direito comparado $\in \mathrm{m}$ atividade nos diferentes países, junto aos estabelecimentos de ensino, têm muitas vêzes ocasionado a decadência, quando não 0 desaparecimento das associações privadas que os houvessem precedido, executando um trabalho de pioneiras para interessar os juristas no estudo dos direitos estrangeiros e lhes mostrar as diversas aplicações possíveis do método comparativo.

Nos Estados Unidos, os estudos de direito comparado encontraram sempre extenso campo de aplicação na diversidade do direito substantivo e adjetivo dos quarenta e oito Estados federados. Nas universidades de Michigan, Chicago, Harvard, Yale, Pensilvânia, Columbia e outras, os estudos comparatistas são amplamente desenvolvidos nas cátedras e nas pesquissas em monumentais bibliotecas, inclusive quanto ao direito soviético e à doutrina socialista em que êle assenta.

Diversas organizações agem no mesmo sentido, como a American Bar Association, a que se devem inúmeras traduções de leis e códigos de países estrangeiros, e a União Pan-americana, para melhor compreensão entre os Estados Unidos e os países da América Latina.

3 A U. N. E. S. C. O. (Organização das Nações Unidas para a Educação, a Ciência e a Cultura) desempenha notável atividade no domínio das ciências sociais, principalmente quanto aos estudos dos direitos estrangeiros, facilitando mesmo a aquisição, por seu intermédio, de livros de um país em outro, sem 
os obstáculos das diferenças de câmbio. Pretende assim mostrar que os malentendidos internacionais encontram sua causa na incompreensão mútua dos juristas e na diversidade das concepções e modos de interpretação do direito, como explica R. DAVID (ob. cit., pág. 402), esclarecendo que, para isso, pareceu necessário à UNESCO enfreritar a constituição dum Comitê Internacional de Direito Comparado, integrado por comitês nacionais que, em cada país, se ponham em contacto com todos os organismos interessados no direito comparado. Seu Secretário Geral, em relatórios periódicos, tem mostrado que o Comitê vem, desde 1949, dando cabal desempenho ao programa que se traçou.

No Rio de Janeiro funciona há anos o Comitê Nacional do Brasil, sob a presidência do professor Haroldo VALLADÃO, insigne internacionalista e comparatista. Em reuniões periódicas, cujas atas são publicadas no Jornal do Comércio, o Comitê passa em revista os principais acontecimentos ocorridos na comunidade internacional, em relação aos domínios do direito comparado, como sejam as atividades comparatistas através de congressos e conferências, de publicações várias, de livros aparecidos e de teses em concurso, como aconteceu em 1953, quando o Comitê Internacional submeteu aos comparatistas de cada país a seguinte tese: "Como o Estado concebe suas responsabilidades em relação às Nações Unidas e às Instituições especializadas, e por que meio cumpre êle as obrigações contratadas e as recomendações das organizações internacionais?"

4 Entre as entidades de caráter privado destaca-se a Acadêmia Internacional de Direito Comparado, fundada em Genebra em 1924 e com sede em Haia, no Palácio da Paz, onde sunciona a Côrte Permanente de Justiça Internacional. Agrupa, seletivamente, apenas algumas dezenas de juristas que, no mundo inteiro, mais se destacam nos estudos de direito comparado, sendo seu único membro titular no Brasil o professor Haroldo VALLADÃO, também único membro titular no Brasil do antigo e prestigioso Instituto de Direito Internacional, já antes referido. 
O objetivo da Acadêmia é "trabalhar para o estudo do direito comparado sôbre a base histórica e para melhorar a legislação nos diversos países, principalmente em matéria de direito privado, mediante a aproximação sistemática e a conciliação das leis".

Além da reunião anual de seus membros e de outras iniciativas, seus principais empreendimentos têm consistido em organizar o Congresso Internacional de Direito Comparado, que já se reuniu, o primeiro e o segundo em Haia, nos anos de 1932 e 1937. Em virtude da grande guerra desencadeada a seguir, a Academia se manteve durante muitos anos em recesso. Retomando depois sua atividade normal, promoveu em 1950 o terceiro Congresso, realizado em Londres, e, em 1954, o quarto Congresso, reunido em Paris.

O 5. ${ }^{\circ}$ Congresso Internacional de Direito Comparado teve lugar recentemente, em agôsto do corrente ano (1958), em Bruxelas, sendo seu Secretário Geral e máximo ativador o professor F. de Sola CAÑIZARES, da Faculdade Livre de Direito de Paris e ex-direitor do Instituto de Direito Comparado de Barcelona, quando publicou a obra em espanhol "Iniciação ao Direito Comparado", prefaciada pelo professor René David.

A propósito, não devemos omitir aqui a referência à participação nossa, como catedrático de direito internacional privado da Universidade do Paraná, no Comitê Brasileiro a êsse Congresso, para o qual contribuimos com dois estudos, traduzidos, em francês e publicados em fascículos, versando sôbre assuntos do seu elevado temário, a saber: "Sentenças estrangeiras de divórcio. Sua homologação e seus efeitos no Brasil", tema de que fomos o relator nacional; e "A possibilidade da unificação do direito privado nos países latinos".

O mencionado Congresso se instalou sob o alto patrocínio do Govêrno Belga e sob os auspícios do Centro Interuniversitário de Direito Comparado e do Instituto Belga de Direito Comparado.

5 Digna de registro é também a iniciativa dos mais eminentes comparatistas francêses que, depois de desenvolverem incessantes esfôrços no sentido de se estabelecer uma coorde- 
nação efetiva entre os mais importantes organismos francêses no domínio do direito comparado, ou sejam a Sociedade de Legislação Comparada, a Sociedade de Legislação Estrangeira do Ministério do Interior e o Instituto de Direito Comparado da Universidade de Paris, criaram, em, 1951, a Fundação denominada Centro Francês de Direito Comparado, constituida dessas três entidades e já reconhecida pelo govêrno francês como estabelecimento de utilidade pública.

Sob os auspícios do citado Centro e do Centro Nacional de pesquisa científica, é publicada periòdicamente a "Revue Internacionale de Droit Comparé". Sob iguais auspícios de ambos êsses "centros", sai a luz o "Annuaire de Legislation Française e Etrangère", compreendendo, em forma condenssada, uma análise das maiores novidades legislativas promulgadas nos diversos países, de modo a apresentar um quadro vivo, tão completo possível, da vida jurídica do universo.

6 Passando ao exame de vários Institutos de direito comparado, vejamos a súmula das finalidades de alguns mais conhecicos. O Instituto de Direito Comparado de Paris, assás prestigioso, assim se define nos seus estatutos, art. $1 .^{\circ}$ : "O Instituto de Direito Comparado, criado junto á Universidade de $\mathrm{Pa}$ ris e filiado á Faculdade de Direito, tem por objetivo o desenvolvimento, sob tôdas as suas formas teóricas e práticas, dos estudos de direito comparado. Constitui para êsse fim um centro de documentação e um centro de pesquisas científicas, de iniciaçãço á pesquisa".

Os meios geralmente postos em prática pelos Institutos de direito comparado, no intuito de preencherem seus objetivos, são, em suma: a) estabelecer, com as instituições científicas nacionais e estrangeiras, da mesma natureza, tôdas as relações úteis ás finalidades visadas; $b$ ) reunir e classificar em forma sistemática os materiais necessários ao desenvolvimento dos seus trabalhos, tais como ementários de legislação nacional e estrangeiras, índices de jurisprudência e catálogos bibliográficos; c) formar bibliotécas próprias ou organizar na biblioteca da Faculdade de Direito, a que estiver ligado, uma seção especializada de doutrina, jurisprudência, material legislativo, 
revistas, boletins, anuários e outras publicações; $d$ ) promover, pela pesquisa e conhecimento do direito estrangeiro, o desenvolvimento do direito nacional, quer na sua legislação, quer na sua jurisprudência; $e$ ) investigar comparativamente os diversos sistemas jurídicos vigentes, tendo em vista a unificação internacional do direito em setores em que ela se apresenta com maior possibilidade; $f$ ) efetuar, nos casos de conflitos internacionais de leis, as necessárias pesquisas para determinar a lei aplicável e seu conteúdo; $g$ ) colaborar em congressos, conferências e reuniões internacionais de assuntos jurídicos; $h$ ) promover inquéritos sôbre os grandes problemas jurídicos da atualidade; $i$ ) realizar conferências públicas de magno interêsse geral e importância internacional; $j$ ) publicar monografías, traduções de trabalhos estrangeiros e uma revista jurídica, mantendo, nesse campo também, intercâmbio com entidades congêneres; $k$ ) conceder ou obter bolsas de estudos para cursos especializados de direito comparado no país ou no estrangeiro; $l$ ) instituir cursos de conferências, conferindo os respectivos diplomas; $m$ ) congregar professôres e estudantes para a pesquisa do direito.

Na Segunda Conferência da UNESCO, realizada no México em novembro de 1947, o Comitê Executivo dessa org̣anização propôs e foi aceito, como uma de suas atividades votadas ao intercâmbio das culturas, no campo das ciências, a preparacão dum plano de estudos do direito comparado e internacional, indicando, como um dos meios de ação, a ajuda que deve ser proporcionada aos especialistas de direito comparado para a realização, entre êles, duma cooperação internacional.

7 O direito comparado abrange uma seara vastíssima de pesquisa e colheita, desbordando, muitas vêzes, dos estudos pròpriamente jurídicos para outros setores das ciências sociais, compreendidos no programa da UNESCO.

A lista dos assuntos que constituiram o objetivo do $5 .^{\circ}$ Congresso Internacional de Direito Comparado, reunido em Bruxelas em agôsto de 1958, contém, na sua seção geral, temas referentes: aos direitos da antiguidade; á história do direito, principalmente quanto á propriedade; ao direito canônico, como seja a forma ordinária e a forma extraordinária do casa- 
mento nos diferentes direitos canônicos; á etnologia jurídica, como seja o problema da redação dos direitos costumeiros; ao direito oriental na India, nos países mussulmanos e outros; á filosofia do direito e á relatividade dos conceitos jurídicos, e $\varepsilon_{c} \mathrm{c}$ estudo do direito comparado, encarado como meio para pesquisar matérias suscetíveis de unificação no plano internacional.

Nas três seções especiais os temas se desdobram com referência ao direito civil, ao direito internacional privado, ao direito rural, ao processo civil, aos direitos intelectuais, ao direito do trabalho, ao direito aéreo, ao direito penal e ao direito internacional público, sendo de notar, quanto a êste, o item relativo á grandeza e decadência da doutrina da não intervenção dos Estados nos negócios internos dos Estados estrangeiros.

O eminente professor H. C. GUTTERIDGE, da Universidade de Cambridge, na sua obra "Le Droit Comparé", tradução franceșa de René DAVID e estudantes do Instituto de Direito Comparado da Universidade de Paris, publicada em 1953, tratando da unidade do método comparativo, mostra que a característica principal do direito comparado, sob êsse aspecto, é que dito método se aplica a tôdas as formas de investigação jurídica. E explica, á página 28: "La méthode du droit est également au service de l'historien du droit, du philosophe du droit, du juge, du praticien, du professeur du droit; et toujours, dans tous ces cas, elle est la même. Elle est la même que l'on envisage le droit public ou le droit privé; l'economiste et le sociologue peuvent y avoir recours comme le juriste. Elle peut rendre d'utiles serviçes à l'homme d'Etat, à l'administration, à l'homme d'affaires".

O renomado professor faz ver ainda, na sua citada obra, que as universidades inglêsas, de alguns decênios para cá, sé dispuseram a agir, encorajando as pesquisas de direito comparado e prestando a essa atividade tôda a ajuda possível, não cbstante os limitados recursos financeiros de que dispõem. $\mathrm{E}$ tanto se faz imprescindível essa ajuda - acentua - porque ela requer tempo, dedicação, gôsto e amor aos estudos árduos. Observa que os jurístas práticos, notadamente advogados e jui- 
zes, não sentem interêsse pelo direito comparado, porque sua principal preocupação é conhecer e dominar as regras de direito que são para êles de interêsse pratico imediato, pois na maior parte do tempo não disporão de lazer nem terão desejo de empreender um gênero de estudos particularmente pesados e que poucas probabilidades apresentem de lhes trazer algum proveito em sua carreira.

A pesquisa científica requer boa disposição de espírito com essa tendência, devotamento, especialização, gôsto, tempo, da parte de quem a ela se dedique, de preferência com exclusividade até de outros misteres, a par dum eficiente aparelhamento técnico, fornecido pelas bibliotecas, inclusive quanto a suas atividades de intercâmbio, de divulgação através do livro e da revista, prestando os pesquisadores ainda valiosos serviços relativamente á sua participação em empreendimentos culturais coletivos, á elaboração legislativa e ao ensino nos cursos de bacharelado, de doutorado e de extensão universitária.

O direito internacional privado, visando a estabelecer normas nacionais de super-direito, para solução de conflitos entre sistemas legislativos diferentes, objetiva igualmente a harmonização internacional dessas normas, enquanto não consegue atingir o ideal da unificação do direito, em boa parte já atingido quanto a certos ramos de mais interêsse prático. Dai constituir a disciplina que, especificamente, maior afinidade apresenta com o direito comparado, a ponto de H. C. GUTTERIDGE afirmar: "Tout comparatiste droit nécessairament connaitre le droit international privé, sinon il ne pourra jamais se rendre compte dans quelle mesure les differences de droit constituent un obstacle aux rapports internationaux". (ob. cit., págs. 65/66).

Na opinião de MARIO SARFATTI, o direito comparado tem por escopo "provocar uma contínua aproximação entre as legislações e extrair, das que se encontram num mesmo gráu de adiantamento, os princípios próprios, a bem dizer comuns, e, assim, empreender a unificação do direito", (Apud prof. JOSÉ NICOLAU DOS SANTOS, no seu estudo "Direito Compa- 
rado e Geografia Jurídica", in Revista da Faculdade de Direito da Universidade do Paraná, 1955, pág. 349).

8 A Faculdade de Direito de Lyon promoveu em 1938 expressiva homenagem a seu antigo professor LAMBERT, de renome universal, por ocasião de seu afastamento da cátedra, em virtude de limite de idade atingido, após quarenta anos de ensino e estudo no campo do direito comparado. Consistiu êsse preito de admiração e reconhecimento na organização e publicação duma vasta e erudita coletânea de estudos versados por especialistas em direito comparado de todos os países, formando grandiosa "Introdução ao Direito Comparado", nome dado á cbra em três alentados volumes de grande formato, com o sub-título explicativo: "Recueil d'Etudes en l'honneur de EDOUARD LAMBERT".

O professor Pierre GARRAUD, no prefácio, explica que a elaboração do "Recueil", na amplitude de seus assuntos, obedeceu ao pensamento do homenageado, que sempre considerou o direito comparado como um domínio comum ás ciências jurídica, economica e social.

Através de seu longo Indice, dividindo a matéria em partes, títulos, capítulos e seções, destacamos as seguintes designações, indicativas da variedade dos temas abordados dentro daquela ampla concepção de LAMBERT: a) história comparativa do direito e etnologia jurídica; b) história do direito e história das religiões; c) a contribuição do direito canônico á ciência do direito comparado; d) a adaptação do direito ás condições econômicas nos direitos europeus e americanos; e) a parte de responsabilidade da ciência jurídica no destino dos povos; g) algumas formas atuais de colaboração internacional no direito penal; h) a interpenetração do direito público e do direito privado; i) o fator econômico na elaboração do direito civil; j) o sindicalismo e a transformação dos princípios fundamentais do direito; k) a obra da Sociedade das Nações e a organização internacional do trabalho; 1) em que medida se poderia recomendar a limitação do direito de propriedade; $\mathrm{m}$ ) as limitações do direito privado na Rússia soviética; n) as no- 
vas fórmulas de regulamentação econômica; o) a organização profissional e o Estado moderno; p) a influência do direito sôbre o contrato de trabalho, etc.

Quizemos mostrar, com essa especificação de assuntos, o vasto âmbito que as pesquisas de direito comparado comportam, afora seus aspectos mais comuns, da órbita do direito privado.

9 Não é só. O Instituto Social Rumaico, de Bucarest, dentro do qual foi organizado, em 1936, um Centro de Altos Estudos Internacionais, que recebeu o apôio financeiro da Fundação Rockfeller, compreende, entre suas seções, as de bibliografia, bibliologia, demografia, ciências econômicas, estudos comparativos, direito, política estrangeira, relações internacionais, teoria política e social, sociologia e pesquisas monográficas.

O professor Mario ROTONDI, fundador e, em seguida, diretor do Instituto de Direito comparado da Universidade Comercial L. BOCCONI, de Milão, em artigo que estampou sôbre essa organização, no "Recueil Lambert" (vol. I), observa, relativamente ao ensino do direito comparado nas faculdades de direitc, que êsse ensino nas cátedras, privado do complemento indispensável dum instituto de direito comparado, é um contrasenso (pág. 111). Escreve ainda aquele acatado comparatista: "Para o estudo e o ensino dos diretores estrangeiros, o instituto é um laboratório onde os livros, muito mais que sua conservação e sua leitura tranquila, servem de instrumentos cotidianos de pesquisas, como as retortas, os microscópios e as balanças dum laboratório, o que leva ás vêzes a modificações radicais nos próprios critérios de economia das bibliotecas". E acrescenta: "Eu creio que não é possível tornar efetiva a realização de tais institutos senão no seio duma organização universitária, que assegura a presença constante duma orientação científica e a colaboração estável dum corpo de assistentes que não sejam distraidos por preocupações de diversas naturezas". (pág. 712).

O ensinamento do citado jurista sugere referência a outro eminente comparatista italiano, o professor Tullio ASCARELLI, da Universidade de Bolonha, o qual, durante a última guer- 
ra, residiu em São Paulo, onde lecionou na tradicional Faculdade de Direito da Universidade, e onde tem retornado com frequência, também em misteres de jurisconsulto. Publicou por essa época, na Revista Forênse, do Rio de Janeiro, vol. 90, de 1942, vários artigos doutrinários em português, sob o título "Premissas ao Estudo do Direito Comparado".

Posteriormente, em 1952, deu á luz seu livro, editado por A. Giuffré, de Milão, "Studi di Diritto Comparato e in Tema di Interpretazione", dedicado aos professores da Faculdade de Direito de São Paulo, da qual recebêra também o título de professor. Nesse livro há dois estudos de particular interêsse para os brasileiros, um intitulado "Osservatione di diritto comparato privato italo-brasileiro", e outro sob o título "Diritti dell'America latina e dottrina italiana".

10 No Brasil os estudos de direito comparado encontraram seu clima propício nas cátedras universitárias da respectiva disciplina, mormente com a criação e funcionamento, de alguns anos para cá, dos cursos doutorado nas Faculdades de Direito da Universidade do Brasil e das Universidades de São Paulo, Recife, Bahia, Minas Gerais, Pôrto Alegre, e, a partir do corrente ano de 1958, na Faculdade de Direito da Universidade do Paraná.

Antes, desde fins do século passado, a matéria fôra lecionada nos cursos jurídicos, não com a amplitude de concepção advinda da orientação modernamente preconisada, sobretudo, a partir do Congresso Internacional de Direito Comparado de Paris, em 1900, onde pontificaram, entre outros, o notabilíssimo SALLEILES. De feição mais acanhada, o seu ensino cingia-se á "legislação comparada". CLOVIS BEVILAQUA, então catedrático da Faculdade de Direito de Recife, publica, em 1893, seu livro "Resumo das Lições de Legislação Comparada sôbre o Direito Privado", com segunda edição em 1897. E CANDIDO DE OLIVEIRA, catedrático da Faculdade Livre de Direito do Rio de Janeiro, publica, em 1903, seu "Curso de Legislação Comparada".

Na prática forense, dos pretórios brasileiros, advogados e juizes, em defesa de seus pontos de vista, limitam, via de regra, 
suas pesquisas, ao procurarem apôio no direito dos países estrangeiros, ás leis dêstes, notadamente seus códigos. Para tanto socorrem-se da preciosa ajuda de eruditos comentadores, como sucede quanto ao direito civil, ramo em que CLOVIS BEVILAQUA, no seu "Código Civil Comentado", menciona em remissão, abaixo de cada artigo, sob verbete de "legislação comparada", os números dos dispositivos análogos de outras legislações.

Entre os comparatistas brasileiros, não se deve esquecer o escritor e magistrado VIRGILIO DE SÁ PEREIRA, com estudos contemporâneos á promulgação do nosso Código Civil. Dos atuais, o professor CAIO MARIO DA SILVA PEREIRA, catedrático de direito civil comparado da Universidade de $\mathrm{Mi}$ nas Gerais, possui alguns trabalhos de introdução á pesquisa, entre os quais um intitulado "Direito comparado, ciência autônoma" (Rev. Forense, vol. 146, pág. 24), em que eruditamente defende a tese já indicada no seu enunciado, para concluir que o direito comparado oferece as características de ciência autonôma, um ramo independente da ciência jurídica, com apôio na autoridade de H. C. GUTTERIDGE, e não apenas dum método de estudos, dum método comparativo, como querem os eminentes professôres René DAVID e T. ASCARELLI.

Em artigo posterior "Direito Comparado e o seu estudo" no tópico referente á concepção moderna da disciplina, após acentuar a tendência antes dominante de donominar de "legislação comparada" as primeiras cátedras brasileiras, o professor CAIO MARIO escreve: "O direito comparado, porém, vê a unidade dos sistemas jurídicos em seu conjunto e deve ter presente, além da legislação, a jurisprudência, o conhecimento do meio social, a prática contratual, a tendência da técnica jurídica (R. DAVID, “Traité El. de Droit Civil Comp." p. 10). 0 direito, ainda nos países de direito escrito como o Brasil, não se limita a êste. Basta atentar em que a norma legislativa tem na verdade o sentido que a interpretação jurisprudencial lhe dá, para se ver que fará trabalho incompleto quem pretenda tirar conclusões apenas dos textos legais com abstração da atividade das côrtes de justiça. Demais disso, a doutrina, a ela- 
boração científica, voando mais alto do que o legislador, e mais desembaraçada do que o juiz, formula a elaboração dogmática das instituições, dando mais idéia do estado de evolução do sistema jurídico". (Rev. da Fac. de Dir. da Un. de M. Gerais, cuto de 1955, pág. 35).

Além do Comitê Nacional do Rio de Janeiro, filiado ao Comitê Internacional da UNESCO, já aludido, existe na Capital Federal, com excelente instalação e magnífica biblioteca, doações do jornalista ASSIS CHATEAUBRIAND, O Instituto de Direito Comparado e Estudos Legislativos, do qual é atualmente presidente o ilustre professor SOARES DE MELO.

Em solenidade inaugural realizada em março de 1948 no Palácio Itamarati e com a presença de altas personalidades, foi fundado também o Instituto Católico de Direito Comparado da Pontifícia Universidade Católica do Rio de Janeiro, tendo o professor SAN TIAGO DANTAS pronunciado nessa ocasião uma conferência sôbre "A unificação internacional do direito privado".

11 Curitiba apresenta condições de ambiente cultural para possuir, a par de outros movimentos já existentes no campo da investigação científica, com apreciáveis resultados práticos, um centro de pesquisa jurídica, através dum instituto de direito comparado. Com três faculdades de direito e ainda faculdades de filosofia e de ciências econômicas, tendo-se iniciado demais disso, no corrente ano, na Faculdade de Direito da Universidade do Paraná, o curso de doutorado, permite o nosso meio o aliciamento e o aproveitamento dos amantes verdadeiros do estudo, entre professores e estudantes e entre os cultores do direito em geral que pretendam dedicar-se ás atividades de pesquisa.

A Universidade do Paraná, nos seus objetivos, tem mesmo por fim "estimular a investigação e a cultura filosófica, científica, literária e artística", conforme seu Estatuto (art. 2. ${ }^{\circ}, \mathrm{b}$ ), que dispõe, ainda: "A Universidade desenvolverá atividades de pesquisa e técnico-cientificas em serviços próprios de cada estabelecimento, em orgãos a êles anexos comuns a dois ou mais, 
ou, ainda, autônomos, conforme couber em cada caso". (art. 38).

Por sua vez, o Regimento Interno da Faculdade de Direito menciona entre suas finalidades, como estabelecimento integrante da Universidade, "estimular a investigação científica e a cultura filosófica do direito". (art. $2 .^{\circ}, \mathrm{c}$ ).

Concluimos assim a tarefa de traçar esta exposição justificativa, com a visão panorâmica das atividades de pesquisa comparatista no mundo ocidental, de modo a aconselhar a fundação do Instituto de Direito Comparado da Universidade do Paraná, cujo ante-projeto de Regulamento igualmente apresentamos para sua apreciação e aprovação pelos orgãos competentes da Universidade. 